Chapter 7

\title{
A Review of Selected Methods of Measurement Used for the On-Line Analysis of Liquid Fuels
}

\author{
Artur Malinowski, Paweł Wrzosek, Anna Turlej and \\ Dorota Wardzińska
}

Additional information is available at the end of the chapter

http://dx.doi.org/10.5772/59804

\section{Introduction}

Liquid fuels are complex, multicomponent mixtures of paraffins, isoparaffins, olefins, naphthenes, and aromatic hydrocarbons having a wide range of molecular weight, as well as heteroorganic components and improvers. The group composition of liquid fuels depends on the initial parameters of raw materials used for making their components and on the characteristics of the respective refinery streams, used in the blending process. Standardization systems exists which are intended to provide fuels with specific, fixed, comparable properties, even for products made in different periods of time and supplied by different manufacturers. Qualitative evaluation involves a number of physico-chemical factors which characterize the properties of fuels during their manufacturing, storage, distribution, and use. Analyses of liquid fuels are intended to confirm their uniform quality, resulting from a number of variables which have an effect on their properties during the product's entire lifecycle.

Liquid fuels are governed by various requirements, depending on their use. Motor fuels are expected to enable the correct operation of the fuel distribution system as well as efficient, costeffective combustion. It is essential to ensure a maximum power, fluidity, and reliable motor operation in different conditions of use. The fuel's composition should be so selected as to reduce toxic emissions into the environment. The quality of liquid fuels available on the wholesale and retail markets is of essential importance to virtually every user of motor vehicles.

Stability of liquid fuels is the essential criterion of their quality during transport and storage. The presence in fuels of diverse individual chemicals may affect their mutual interactions. The presence of unsaturated compounds and biocomponents in fuels does not seem to improve 
their resistance to ageing processes. Sufficient stability can be provided by addition of a wide range of improvers which slow down the dynamics of the various processes taking place, while modifying compositions and physico-chemical parameters. Improvers tend to reduce the blend's reactivity: a fuel with improvers will not tend to undergo quick physico-chemical changes when inside storage tanks or tankers, and its components will be less susceptible to oxidation processes.

It is not feasible to obtain a fuel which has all those properties at a time: they exclude one another. A maximum engine power is typically achieved in return for increased emissions and higher consumption of fuel. Reduction of the environmental impact of fuels is connected with optimization of the combustion process. Improvement of fuels in respect of their physicochemical parameters has a positive impact on their functionality in operating conditions although, on the other hand, it may have an adverse effect on their stability during storage.

Blending of liquid fuels requires the implementation of assorted technological procedures in order to attain the final compromise: compliance with normative requirements and provision of desirable properties to fuels. This requires the knowledge of the characteristics and dynamics of changes in the physico-chemical properties of commercial fuels and their individual components. Applicable analyses, which confirm compliance of the properties of gasolines and oils with normative requirements, are carried out by accredited organizations to guarantee quality to the users of the liquid fuels available in the market.

Faster and less expensive, alternative methods to analyze fuels are required. The market is calling for rapid developments in fast and inexpensive fuel analyzers. This type of devices have the essential advantage of requiring a small sample volume only, short duration of analysis and no extra chemical reactants. The various methods are described and selected types of commercially available equipment are presented in the chapters which follow. Moreover, the possibility of adaptation of classical nephelometry method to measuring the selected parameters of fuels using optoelectronic sensors, developed at the Regional Office of Measures (OUM) in cooperation with scientists at PIMOT (Automotive Industry Institute, formerly Institute for Fuels and Renewable Energy), Warsaw.

\section{Normative fuel testing methods}

According to European standards, liquid fuels are required to comply with certain qualitative requirements in every step of their lifecycle, including their manufacturing and use. Such standards are a set of requirements concerning the quality of fuels. They establish testing methods which enable verification of their properties.

Qualitative requirements concerning the physico-chemical properties of liquid fuels are amended in accordance with applicable legislation and are affected by changes in engine designs over the years. Such factors involve the necessity to eliminate any sulfur compounds from gasolines and oils, therefore, the presence of sulfur is constantly monitored. Any other heteroorganic particles that may be present in the improved fuel in addition to sulfur are 
eliminated by commonly used sulfur removal technologies. In the long run, there has been a tendency to lower the permissible limits for aromatic compounds in fuels and for olefin hydrocarbons in gasoline. Elimination from engine fuels of compounds which contain unsaturated bonds and heteroelements has a direct effect on deterioration of parameters which are responsible for the lubricating properties of fuels. The quality of fuels is improved by addition of suitable improvers. Both the content of aromatic hydrocarbons in fuels and their lubricating properties are issues to which normative studies, carried out by accredited laboratories, are dedicated.

Motor fuels are expected to comply with many requirements which affect the safety and comfort of vehicle users. The performance properties of liquid fuels and their stability during storage and transport are determined by the percentage of the respective groups of chemicals in them.

The qualitative properties of liquid fuels are related to engine type: type of ignition and manner of combustion of the fuel blend. Gasoline is expected to be characterized by suitable volatility to provide an optimum fuel blend and to guarantee its knock-less combustion in the engine. Requirements being posed to diesel fuels are mainly connected with providing the correct functioning of the entire supply system, efficient combustion in various engine operating conditions, suitable lubrication, and the correct low-temperature parameters. Moreover, motor fuels are expected to display physical and chemical stability during their entire lifecycle, not to pose environmental hazard, and to generate only minimized harmful emissions in the process of combustion. Occasionally, those parameters which determine fuels' high operating quality, are not desirable in the aspect of storage, transport or safety in its wide sense, and conversely - those properties which are desirable during storage and transport may not be desirable in the aspect of use.

The physical and chemical characteristics of fuels as well as their performance properties are determined by the structure of hydrocarbons. For instance, the degree of fuel atomization in the combustion chamber depends on its density, viscosity, and surface tension, and is the higher, the lower the values of those parameters. The parameters are monitored in order to provide liquid fuels with a suitable quality. In aromatic compounds, the values of the above mentioned parameters are higher, compared with isoparaffins and paraffins - typical components of gasolines and diesel fuels, respectively. Therefore, their variable concentration in fuels, as shown by the characteristics of the refinery streams used for fuel blending, affects the performance properties of fuels.

Volatility of liquid fuels is an important parameter for the gas phase formation process just after a fuel is injected into the combustion chamber, and it also helps avoid excessive losses during storage, transport and distribution. The optimum level of evaporation is made up of the fuel's heat of evaporation and vapor pressure. Volatility index, an important quality indicator for gasolines, is evaluated based on the normative assessment of fractional composition, that is, determination by normal distillation of the fuel volumes which boil at the stated temperature ranges, and of vapor pressures - a supplementary indicator of volatility. In the case of gasoline as well as diesel fuel, the respective fraction percentages per unit of volume determine not only their behavior during the engine starting, formation of air-fuel mixture, 
and combustion process, but also their tendency to form carbon deposits in operating conditions, deposits in stationary conditions, and harmful emissions into the atmosphere during storage and operation.

Liquid fuels have different chemical compositions, depending on the type of engine they are designed for. Although the combustion process is different for gasoline compared with diesel fuel, the important thing is that the air-fuel mixture should be a uniform and complete process regardless of the engine design and ignition. Resistance of gasoline to detonation combustion, as expressed by the octane number, is a normative parameter indicating the quality of gasoline. The tendency of a fuel to undergo spontaneous ignition in certain conditions is used in commonly used diesel engines; it is shown as the fuel's cetane number. According to applicable standards, the research octane number (RON) and motor octane number (MON) for gasoline and cetane number for diesel fuel are established in standard, single-cylinder engines with variable compression ratio.

The stability of liquid fuels during storage is directly related to their chemical composition. The reason why fuel ageing occurs is that processes take place gradually in them, leading to changes in their physico-chemical properties. Typical ageing processes in liquid fuels occur due to oxidation. The chemical compounds that are present in fuel blends change their properties, color and smell. Ageing processes taking place in fuels lead to higher levels of organic acids, as indicated by the acid value which says how much potassium hydroxide is required for neutralizing acid substances present per unit of fuel. Typically, the test is used for assessing degradation of oils. The aggregation of oxidation products along with unsaturated and aromatic compounds present in fuels leads to the formation of high-molecular, viscous substances. High molecular weight, often resulting from polymerization and polycondensation, causes the formation of deposits. Such deposits tend to plug filters, suction tubes, and lead to the formation of carbon deposits, disturbing engine operation. Indirectly, the loss of valuable components from the fuel blend leads to reduced octane or cetane values, which is undesirable: the fuel's commercial value is affected, its further use becomes dangerous and may damage engine components. To establish the amount of deposit, tests are carried out to determine inherent gums, especially in gasoline. Not only the presence in fuels but also the tendency of fuels to form gums is an important issue. The resin content is an indicator, used for determining oxidation stability of gasoline under operating conditions. During distribution, oxidation stability is indicated by what is called induction period: the time during which a fuel, subjected to the effect of oxygen, will not react in conditions referred to in the applicable standard. The tendency of diesel fuels to form carbon and other deposits is assessed by the normative method to determine coking residue and ash residue after incineration.

The permissible limits of contaminants, sulfur, water or heavy metals in fuels are governed by applicable standards. The parameters evaluated include the effect of fuels on the corrosion of metal parts, connected with the presence of organic acids, sulfur compounds, and water in the fuel. The corrosive effect is evaluated using a copper plate in the water bath in standardized conditions (EN ISO 2160).

Gasolines and diesel fuels have also some individual features which provide fuels with a functional value. Those intended for use in engines with a different design or method of 
operation have the appropriate, different chemical composition. Therefore, quality control involves a number of parameters which affect both the performance of liquid fuels and their properties in the aspect of logistics.

The use of normative control conditions and methods is meant to provide fuels originating from different sources with the desirable quality. However, such analyses are time- and laborconsuming and quite costly: they require rather large samples, which are to be collected as prescribed in the applicable standard, and a series of analyses using specialist equipment are to be carried out by qualified personnel. The long duration and high cost of such analyses in accredited laboratories may, at times, be a stimulus for seeking less expensive and faster analyses of the quality of liquid fuels.

In addition to the high costs, such analyses have the disadvantage of long duration and difficulties in the comprehensive interpretation of results, leading to the unambiguous classification of the performance of the specific fuel sample. A fuel analysis according to the standards EN 590 for diesel fuel and EN 228 for gasoline takes not less than several days.

\section{The test methods, used for the on-line analysis of liquid fuels}

Recent years have seen the development of alternative methods to the costly and complicated laboratory analyses: such methods are applied in universal fast fuel analyzers. Fast analysis is very important in the qualitative evaluation of fuels, used for refueling vehicles with advanced drive units. Using a poor quality fuel may, at best, result in having to clean the fuel system; in the worst case, it may cause permanent damage to the engine and the injection system [1, 2]. Commercially available fuel analyzers are based on a wide array of analytical methods, representing different levels of technological advancement.

\subsection{Spectral analysis}

Infrared (IR) spectroscopy is a commonly used advanced method for optical analysis of liquids. It is based on the interactions between the particles of matter and the electromagnetic field. The specificity of electromagnetic waves enables interactions with those particles in which polar bonds are present. When passing through a sample, part of radiation is reflected. The absorbed quantity of such radiation depends on the level of energy and the type of matter it interacts with. If molecular bonds are devoid of a dipole moment, the result is that there is no active interaction between matter and infrared radiation, and the IR spectrum is not generated. Information about the structure of particles is obtained by determining the quants of energy absorbed [3].

In the structural examination of organic compounds, the range of radiation, typical of the specific infrared $\left(4000-400 \mathrm{~cm}^{-1}\right)$ is the most significant. Absorption of radiation in that range leads to changes in the rotation and oscillation energies of molecules. The use of absorption of radiation in the mid-infrared range provides information about the structure of a wide array of chemical compounds with a variety of properties. Infrared spectroscopy belongs in the non- 
destructive category of physico-chemical methods, therefore, a number of data may be obtained using a small quantity of test material.

Contemporary spectroscopic methods are based on advanced information technology in the area of recording interference images followed by its transformation into a spectrum using the Fourier transform. FT-IR spectroscopes are characterized by high sensitivity, resolution, and easy data processing. Compared with classical methods based on the diffraction network and dispersion, the advanced Fourier-transform methods offer a much higher precision. Contemporary devices use the Michelson interferometer to generate spectra; its design enables the passage of a larger quantity of radiation, compared with classical equipment. The solution has the advantage of the continuous detection of a wider radiation band. The FT-IR method generates a top quality spectrum from a small sample, and in a short time.

In IR spectroscopy, the structure of the components of petroleum fractions is established based on the specific absorption bands in the infrared radiation range for the respective functional groups. The structure and size of substitutes in the molecules may cause a minor shift of the band locations within the spectrum. Changes in the position of the absorption bands and changes in their shape, which reflect the molecular environment of a compound's functional group, may indicate important structural details, whereby they may have a significant effect on substance identification.

A qualitative analysis of the composition of mixtures can be performed using reference spectra, which are available for the users' convenience in the form of computerized databases or libraries. Oscillation spectra are typical of a given molecule and enable its explicit identification. A quantitative compositional analysis is based on the Lambert-Beer law which says that band intensity in the spectrum is proportional to component's concentration in the mixture.

IR spectroscopy is widely used for substance determination and identification in laboratories and for quality control in industry. Furthermore, it is useful in forensics.

A combination of IR spectroscopy and multi-dimensional calibration is used for predicting the physico-chemical properties of fuels and validation of their authenticity [4,5]. The use of nearinfrared spectroscopy (NIR) for determination of the content of soy biodiesel in conventional diesel fuel was described by Knothe [4].

In [5], the authors proposed the use of absorption spectroscopy for detecting adulteration of gasoline (in the case of Jordanian gasoline types - by addition of the cheaper RMG to the more expensive, unleaded UMG gasoline). In the comparative analysis of the spectra, recorded for the prepared blends with different unleaded-to-leaded gasoline ratios, 13 characteristic bands were selected of which the intensity varied with changes in the content of RMG. Using multidimensional calibration, it was found that contamination of a given sample of unleaded gasoline with leaded gasoline can be proved and its quantitative determination is possible.

The applicability of FT-IR spectroscopy in determination of the physico-chemical properties of fuels is the subject of numerous reports. The obtained spectra and methods of mathematical analysis were used for finding the values of $\operatorname{RON}$ and $\operatorname{MON}[6,7,8]$ or the content of oxygen compounds [9]. 
Interesting studies are reported in [10]. The objective was to establish 10 parameters of gasoline from the spectra obtained using near infrared absorption spectroscopy and chemometrical methods. The target parameters included RON, MON, vapor pressure, API index, content of aromatics, olefins, and benzene, and other ones.

Examples of devices used for the on-line analysis of fuels include IROX 2000 [11] - a medium IR range spectrometer, used for an automated measurements of essential parameters of gasoline. The device has a mathematical model implemented in it which enables determination of such parameters as octane number, fractional composition, vapor pressure, etc. IROX Diesel is a variety of the device, dedicated to measuring the respective parameters of diesel fuel, such as: cetane number, cetane index, FAME content.

Eraspec [12] from Eralytics (Fig. 1) is another example of the solution: a universal multifunctional apparatus, designed for the spectral analysis and assessment of the parameters of diesel fuels and gasoline.

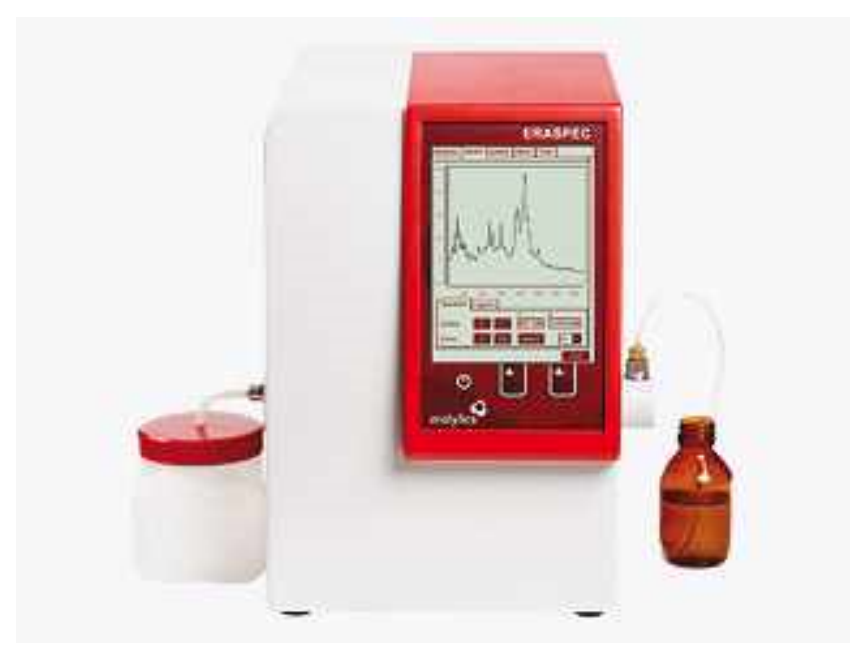

Figure 1. Eraspec - fuel analyzer from Eralytics [12]

Eraspec is dedicated to the measurement of such parameters of liquid fuels as: octane number, cetane number, content of FAME, distillation fractions, and other ones.

\subsection{Raman spectroscopy}

Raman spectroscopy is another method, applicable in the on-line analysis of fuels. Same as IR spectroscopy, it is designed to provide information about molecular structure, that is, about the interactions between the atoms in molecules. Raman spectroscopy is based on the Raman effect: the phenomenon of non-elastic diffusion of radiation by the sample [13, 14]. Even though it was discovered nearly 90 years ago, the method was developed only after the use of lasers and computers with higher computational capabilities. The mechanism which causes the 
Raman effect is quite different from the mechanisms based on infrared analysis, functioning in other techniques; therefore, water molecules in the sample do not interfere with the spectra recording. The method has one great advantage: it is not necessary to collect a sample, the analysis may take place in-situ, using probes which are immersed directly in the fuel [15]. Owing to the use of light pipes, the probe may be located as far as hundreds of meters away from the fuel analyzer. This eliminates the necessity to introduce live parts in fuel storage tanks, which otherwise would pose a realistic threat in explosion hazard zones [15].

Raman spectroscopy was used, for instance, in studies carried out by Shoute's research team, analyzing a range of petroleum products (such as commercial gasoline). The authors reported results which show that the so-called "finger-print region" of the spectra is very characteristic and may be useful for the qualitative identification of mono-, bi-, tri-, and polycyclic aromatic hydrocarbons. Preliminary tests of commercial gasoline samples indicate that Raman spectroscopy may be used by refineries or fuel suppliers for identification of gasolines of unknown origin [16].

Gorelik's research team examined a series of motor gasoline with the octane numbers 80, 92 and 95. Correlations between spectra were analyzed for gasolines and saturated hydrocarbons. It was found that Raman spectra for various types of gasoline showed certain discrepancies, resulting from compositional differences between gasolines with respect to hydrocarbons, including aliphatic and cyclic hydrocarbons. The authors showed that even small band frequency shifts could be observed, depending on the number of carbon atoms in the hydrocarbon chain. Owing to the resemblance of Raman spectra for saturated hydrocarbons and gasolines, they demonstrated the usefulness of Raman spectroscopy in the compositional analysis of gasoline and other petroleum products [17].

Raman spectroscopy may be used for the identification and classification of fuels in qualitative analysis [18]. Scheng's research team have examined 128 gasoline samples, originating from three refineries and having different octane numbers (90, 93 and 97). The authors demonstrated that it was possible to identify the brand of the gasoline samples and to find their correct octane numbers using the spectra obtained and the mathematical analysis methods available (LeastSquares Support-Vector Method).

In [19], Raman spectroscopy was used for the rapid quantitative detection of ethanol in gasoline. Spectra were obtained for blends with various ethanol-to-gasoline ratios as well as for pure substances. From the results obtained, two bands were selected (the $1030 \mathrm{~cm}^{-1}$ band for gasoline and the $912 \mathrm{~cm}^{-1}$ band for ethanol), of which the intensities could be linked quantitatively with the content of ethanol in the ethanol-gasoline blends.

Raman spectroscopy solutions dedicated to the on-line analysis of fuels are known and available. Process Instruments offers a number of Raman analyzers for laboratory and industrial applications. Using chemometrical methods, a number of parameters, including octane number, cetane number, fractional composition, or content of oxygen compounds, are measured based on the recorded spectra. Based on the location and surface area of typical peaks, especially in the so-called "finger print region", the content of benzene, toluene, MTBE, aromatic compounds or olefins are found in the fuel sample (Figure 2). The manufacturer also 
offers a PI-200 Raman Analyzer applicable to the laboratory analyses of fuels. E-Z-RAMAN is intended for industrial applications [15].

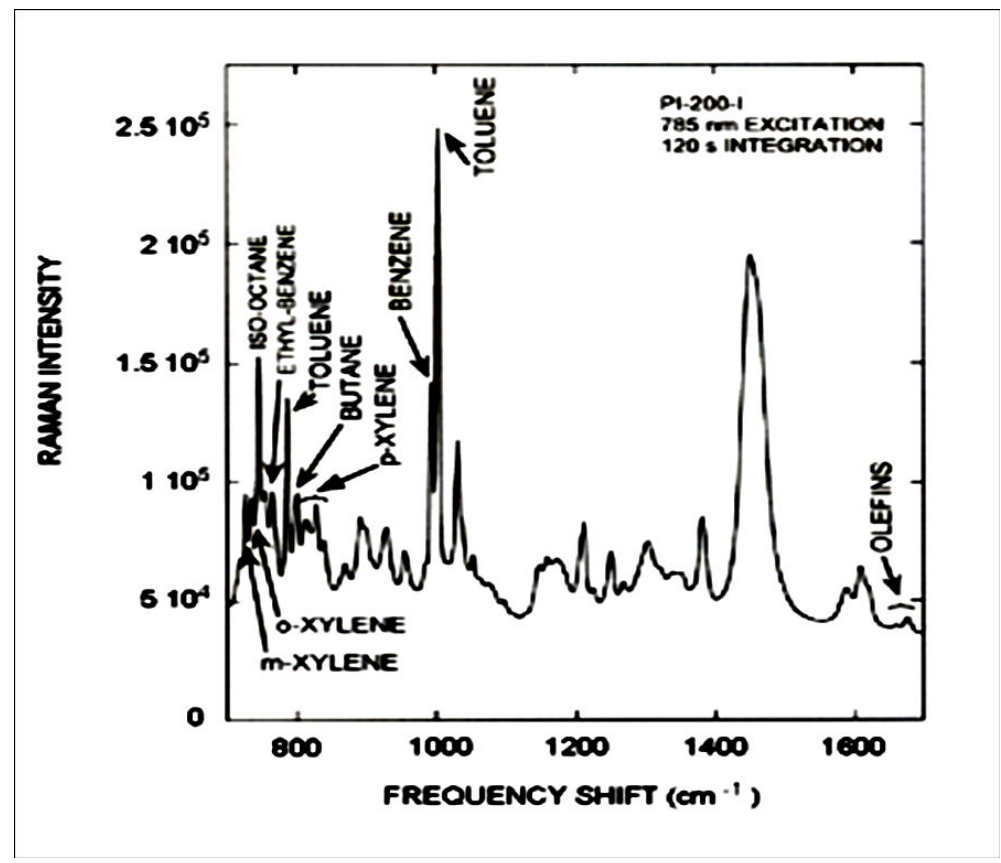

Figure 2. A Raman spectrum fragment with typical peaks [15]

An interesting solution is offered by Real Time Analyzer: the company developed, for the US Army, a compact, portable, case-size fuel analyzer based on Raman spectroscopy [20]. It has an incorporated spectra library which enables fuel identification based on the recorded spectrum (gasoline, diesel fuel, aircraft fuel) as well as its qualitative verification with respect to the applicable normative requirements (compliant/non-compliant).

\subsection{Permittivity measurement method}

Another interesting fuel analysis solution was proposed by Delphi and has obtained patent coverage. The method is based on the permittivity phenomenon. The device uses the radio frequency oscillator technology, measuring complex permittivity with a tranducer placed in the fuel sample. The solution is quite new and details of the technology are not commonly available yet. The method was used in the YDT553 analyzer [21], of which a picture is shown in Figure 3.

The YDT553 fuel analyzer enables the immediate determination of any unacceptable level of esters or contaminants in the fuel sample. This type of analysis was previously restricted to analytical laboratories only. The fuel analyzer is useful to the personnel of service stations 


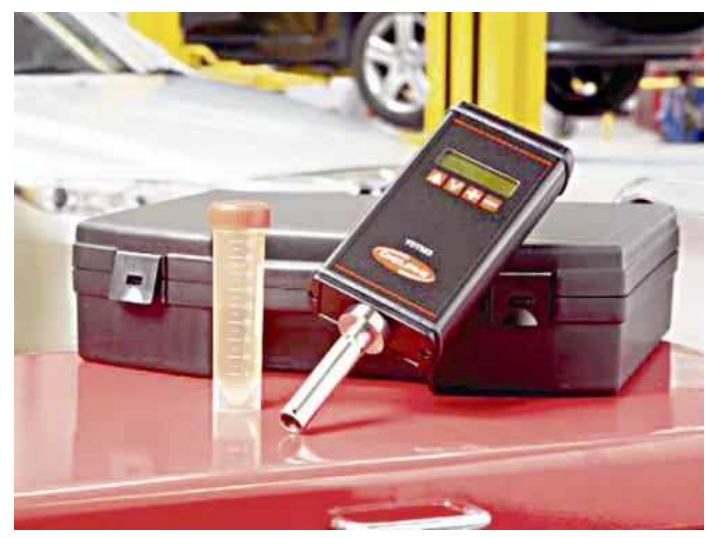

Figure 3. YDT553 fuel analyzer from Delphi

where fuel injection systems are repaired, who are able to use the device for the quick verification of the quality of the fuel in the vehicle tank.

\subsection{Nephelometry}

Liquid fuels may also be examined using the nephelometric method. The method consists in the turbidity analysis of solutions based on the measurements of transmission and scattering of light after passing through a given test sample. In addition, the range of parameters to be determined by the classical nephelometric method is significantly extended by the use of optical capillaries, that is, thin glass pipes as measurement cells. They have the specific ability of fluid elevation and light conducting inside the capillary and in the walls, which makes them an excellent choice for an analysis of the parameters of liquids. The filled optical capillary forms a liquid light pipe where the light propagation conditions in the pipe as well as in the pipe walls depend on the filling substance, especially on the difference between the refractive index values for the capillary filling and for the capillary material [22]. This enables identification of the refractive index as well as determination of other parameters of the liquid, such as turbidity and concentration of solutions after diluting them with a known solvent. In the case of transparent liquids, the test may be limited to turbidimetry, rather than using the nephelometric method. In this way, the liquid analysis is reduced to an analysis of the classical liquid light pipe, which is constituted by the liquid filling the entire capillary volume.

Optical capillaries may be equipped with zone heating of the liquid in the capillary: this extends the test method by evaluation and classification of the liquid's parameters. The idea of the liquid zone heating is shown in Figure 4.

The passage of current through a resistive heater causes evaporation in the capillary region, which is accompanied by the formation of a liquid vapor bubble. The stability of the bubble depends on the ratio between the vapor pressure and the pressure being generated by the surface tension forces. The specific vapor pressure for a given liquid is determined by the pressure at which the gas is in equilibrium with the liquid. The pressure depends on the type 


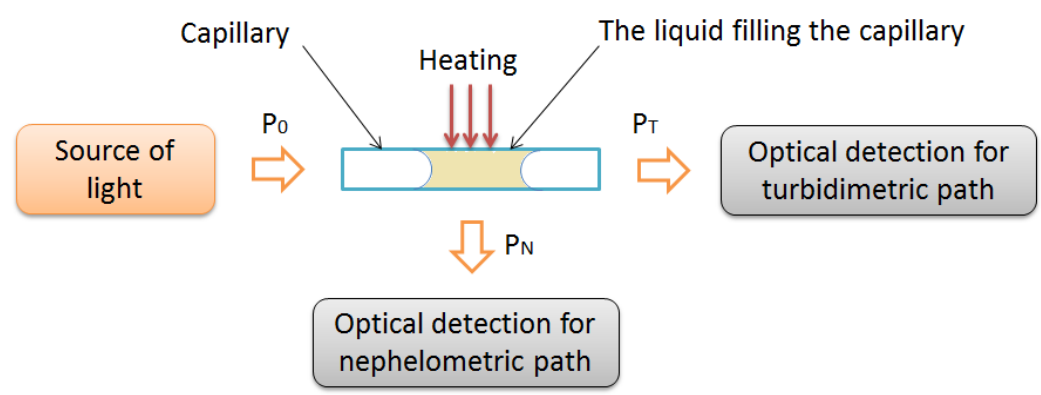

Figure 4. Modified classical nephelometric system, with the zone heating technique.

of liquid and on temperature: the higher the temperature, the higher the pressure of saturated vapor. In the course of heating in the capillary, the vapor pressure is counteracted by the pressure resulting from surface tension forces. Heating of a portion of the capillary causes rapid evaporation, leading to the formation of regions, filled with the liquid vapor. The resulting vapor bubbles form a liquid-vapor interface and the resulting lens effect, having a specific (for a given liquid) impact on signal propagation in the turbidimetric and nephelometric paths.

The measurement of light transmission changes, performed in a repeatable manner for a given liquid in the cycles before heating / in the course of heating / after switching off the heater, of which the results are compared with the appropriate standard characteristics enable identification of the liquid type or analysis of changes in its parameters.

\section{The use of optoelectronic sensors for analysis of gasoline}

Optoelectronic sensors for the analysis of selected properties of fuels were developed by OUM in cooperation with researchers from PIMOT. Gasoline types for spark ignition engines, being commonly available from fuelling stations, were selected for the analysis of fuels using such optoelectronic sensors. Figure 5 shows the results of analysis of three different samples of gasoline, originating from different manufacturers (samples A and B with the octane number of 95 and sample $C$ with the octane number of 100). The phase curves for the 95 octane gasoline samples A and B are similar: same transmitted optical powers, phase separation induction times, and similar power transmission changes during and after heating may indicate similar compositions and octane numbers, which is 95 for the two gasoline samples. The curve for the gasoline sample $\mathrm{C}$ with the octane number 100 is slightly different. The higher octane number for sample $C$ causes a longer phase separation time, which is typical of fuels with higher octane numbers.

Higher octane numbers tend to reduce the risk of the undesirable phenomenon of knocking combustion of fuels [23]. 


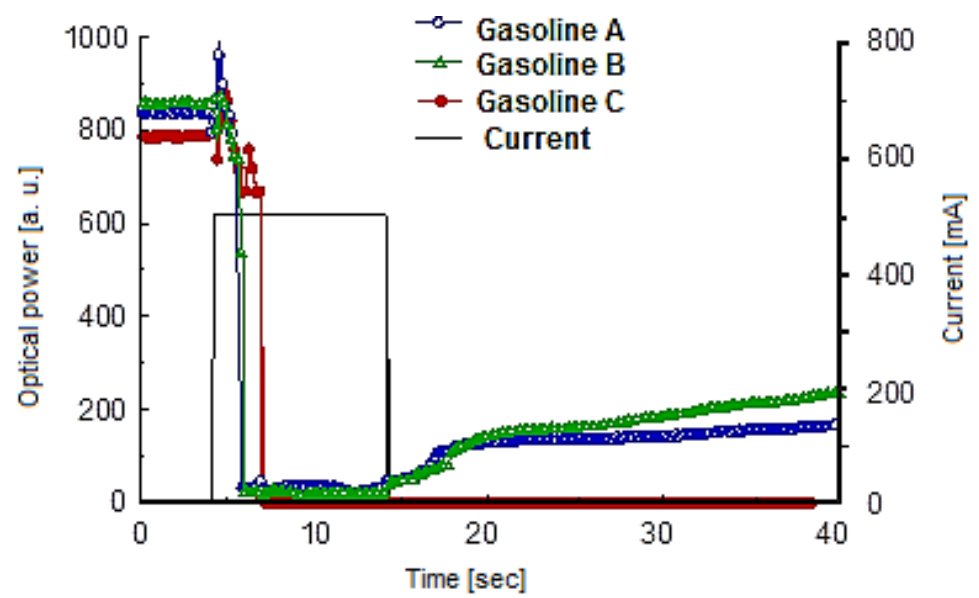

Figure 5. Results of transmission measurements for gasolines A, B and C vs. time and heater current

\section{Results of tests for biodiesel}

The test method was also used for the analysis of pure biodiesel and of a mixture of conventional diesel fuel with FAME. The test samples included biodiesel B20 (20\% FAME and B100), and the test results are shown in Figure 6.

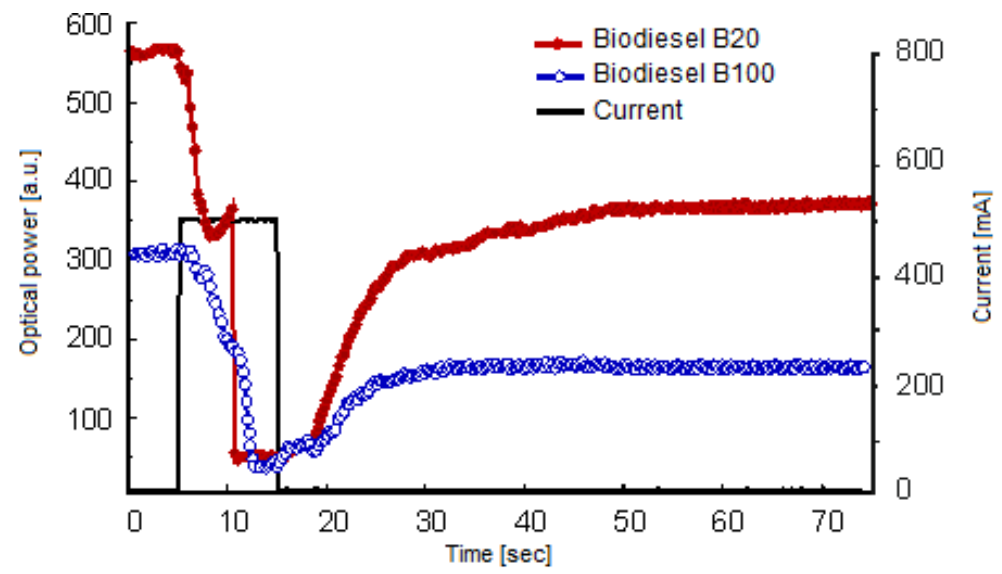

Figure 6. Results of transmission measurements for Biodiesel B20 and B100 vs. time and heater current

A comparison of the transmission results for the diesel fuel samples indicates that addition of biocomponents leads to a loss of power in the transmission path, causes changes in the time and shape of the phase separation curve. Comparison of biodiesel B20 and B100 indicates that after addition of biocomponents to the diesel fuel samples, the power transmission in the turbidimetric path was approx. 50\% lower. The above characteristics show that analysis of 
power transmitted before/during/after the heater operation provides, in a short time, explicit information about the quantity of biocomponents added to the fuel.

\subsection{Measuring the repeatability of results of the measurement method}

Table 1 shows the results of a repeatability analysis for 12 measurements of average optical power in the turbidimetric path and standard deviation for samples of liquid fuels before, during and after the resistive heating. The analysis was carried out for diesel fuel, diesel fuel with 20\% FAME, biodiesel, and for a diesel fuel blend with biodiesel.

\begin{tabular}{lcccccc}
\hline & \multicolumn{2}{c}{ Before heating [a.u.] } & \multicolumn{2}{c}{ While heating [a.u.] } & \multicolumn{2}{c}{ After heating [a.u.] } \\
\hline Fuel & Average value & $\begin{array}{r}\text { Standard } \\
\text { deviation }\end{array}$ & Average value & $\begin{array}{l}\text { Standard } \\
\text { deviation }\end{array}$ & Average value & $\begin{array}{c}\text { Standard } \\
\text { deviation }\end{array}$ \\
\hline Diesel fuel & 702.60 & 0.86 & 72.94 & 4.72 & 379.37 & 8.01 \\
\hline Biodiesel B20 & 568.45 & 0.85 & 54.76 & 1.45 & 368.31 & 17.19 \\
\hline Biodiesel B100 & 309.22 & 0.76 & 38.57 & 2.65 & 189.92 & 1.32 \\
\hline $\begin{array}{l}50 \% \text { diesel fuel plus } \\
\text { Biodiesel B100 }\end{array}$ & 455.33 & 0.70 & 46.29 & 3.53 & 264.12 & 1.72 \\
\hline
\end{tabular}

Table 1. Repeatability of results of measurement of average optical power in the turbidimetric path for fuel samples before, during, and after resistive heating

The measurement results are illustrated in Figure 7.

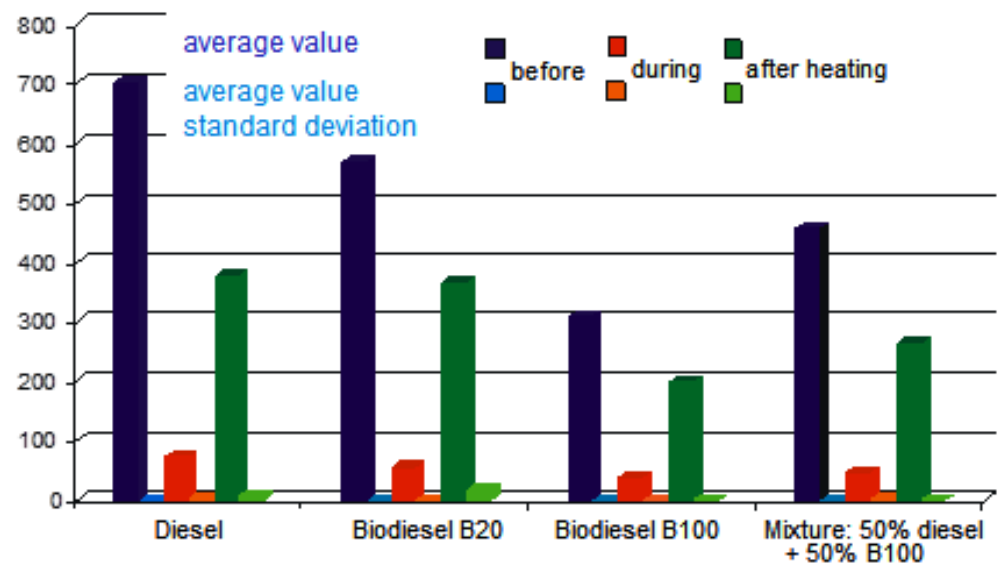

Figure 7. Graphical representation of results of repeatability analysis for a series of 12 measurements of average values of optical power and standard deviation for fuel samples before, during, and after resistive heating

The analysis indicates that the measurement method is characterized by a very high repeatability, as shown by low average value standard deviations, especially before the heating process. 


\section{Conclusion}

The development of an electronic device enabling the measurement and/or scanning of the parameters of fuels seem to be very important for the fuel economy and for the end user. In view of price rises in the fuel market, the consumers are expecting simple and inexpensive fuel analyzers or fuel quality indicators, enabling them to control fuel quality or to measure its biocomponent concentration when refueling. It is to be remembered that new biocomponents or advanced, second generation fuels based on renewable resources may be invented. Fast assessment of fuel quality is important in the aspect of fuelling advanced engines, in which poor fuel quality may reduce the engine's lifetime or - in the extreme cases - lead to damage.

The innovative fuel analyzer based on optoelectronic sensors may be a desirable alternative in uses where normative analyses are not required. At the present stage of research, the existing results seem promising on the way to the target end result which is a cost-effective, universal fuel quality analyzer.

\section{Author details}

Artur Malinowski ${ }^{1}$, Paweł Wrzosek ${ }^{2}$, Anna Turlej ${ }^{1}$ and Dorota Wardzińska ${ }^{1^{*}}$

*Address all correspondence to: d.wardzinska@pimot.eu

1 Department of Fuels, Biofuels and Lubricants, Automotive Industry Institute, Poland

2 Regional Office of Measures, Poland

\section{References}

[1] Mekisz J., Pielecha I., Alternatywne napędy pojazdów, Wydawnictwo Politechniki Poznańskiej, Poznań, 2006.

[2] Postrzednik S., Żmudka Z., Termodynamiczne oraz ekologiczne uwarunkowania eksploatacji tłokowych silników spalinowych, Wydawnictwo Politechniki Śląskiej, Gliwice, 2007.

[3] Collective work, Ed. W. Zieliński, Metody spektroskopowe i ich zastosowanie do identyfikacji związków organicznych, Wydawnictwo Naukowo-Techniczne 2000

[4] Knothe G., Determining the blend level of mixtures of biodiesel with conventional diesel fuel by fiber-optic near-infrared spectroscopy and $1 \mathrm{H}$ nuclear magnetic resonance spectroscopy. J Am Oil Chem Soc 2001;78:1025-8. 
[5] M.A. Al-Ghouti, Y.S. Al-Degs, M. Amer, Determination of motor gasoline adulteration using FTIR spectroscopy and multivariate calibration, Talanta 76 (2008) 11051112

[6] P. E. Flecher, W. T. Welch, S. Albin, J. B. Cooper, Determination of octane numbers and Reid vapor pressure in commercial gasoline using dispersive fiber-optic Raman spectroscopy, SpectrochimicaActa Part A: Molecular and Biomolecular Spectroscopy Volume: 53, Issue: 2, February, 1997, pp. 199-206

[7] J Kelly, CH Barlow, TM Jinguji, JB Callis, Prediction of gasoline octane numbers from near-infrared spectral features in the range, 660-1215 nm. Anal Chem 1989;61, pp. 313-20.

[8] G. E. Fodor, K. B. Kohl, R. L. Mason, Analysis of gasolines by FT-IR spectroscopy. Anal Chem 1996;68, pp. 23-30.

[9] A. Iob, R. Buenafe and N. M. Abbas, Determination of oxygenates in gasoline by FTIR, Fuel Vol. 77, No. 15, pp. 1861-1864, 1998

[10] I. Litani-Barzilai, I. Sela, V. Bulatov, I. Zilberman, I. Schechter, On-line remote prediction of gasoline properties by combined optical methods, AnalyticaChimicaActa Volume: 339, Issue: 1-2, February 28, 1997, pp. 193-199

[11] Grabner Instruments, IROX 2000 Fuel Analyzer, User Manuals, Grabner Instruments MesstechnikNfg. GmbH \& Co KG, 1220 Vienna, Austria, 2010.

[12] Eralytics GmbH, Lohnergasse 3, A-1210 Vienna, Austria, 2010.

[13] Collective work, Ed. W. Zieliński, Metody spektroskopowe i ich zastosowanie do identyfikacji związków organicznych, Wydawnictwo Naukowo-Techniczne 2000

[14] Smith E., Dent G.: Modern Raman Spectroscopy - A Practical Approach. John Wiley \& Sons Ltd, 2005

[15] Information from Process Instruments INC, www.process-instruments-inc.com

[16] L.T.C. Shoute, K. J. Schmidt, R. H. Hall, M.A. Webb, S. Rifai, P. Abel, P. H. Arboleda, A. Savage, J. T. Bulmer, G. R. Loppnow, UV Raman Spectroscopy of Oilsands-Derived Bitumen and Commercial Petroleum Products, Applied Spectroscopy, vol. 56, issue 10, pp. 1308-1313

[17] V. S. Gorelik, A. V. Chervyakov, L. V. Kol'tsova, S. S. Veryaskin, Raman spectra of saturated hydrocarbons and gasolines, Journal of Russian Laser Research, July-August, 2000, Volume 21, Issue 4, pp. 323-334

[18] L. Sheng, D. Lian-kui, Classification of gasoline brand and origin by Raman spectroscopy and a novel R-weighted LSSVM algorithm, Fuel, Volume 96, June 2012, pp. 146-152 
[19] Qing Ye, QinfengXu, Yongai Yu, Ronghui Qu, Zujie Fang, Rapid and quantitative detection of ethanol proportion in ethanol-gasoline mixtures by Raman spectroscopy, Optics Communications 282 (2009) pp. 3785-3788

[20] Information from Real Time Analyzer

[21] Delphi Customer Technology Center, L-4940 Bascharage, G.D. Luxembourg, Press Releases, Release Date: September 14, 2010.

[22] Dragavon J., Burgess L., Detection technologies in micro-fluidic systems for the single cell metabolomics and other applications, Center for Process Analytical Chemistry University of Washington, 2005

[23] Hoogers G., Fuel Cell Technology Handbook, CRC Press, Boca Ration, New York, 2003. 